\title{
Genetic risk for atrial fibrillation could motivate patient adherence to warfarin therapy: a cost effectiveness analysis
}

\author{
Dov Shiffman ${ }^{1 *}$, Marco V. Perez², Lance A. Bare', Judy Z. Louie', Andre R. Arellano ${ }^{1}$ and James J. Devlin ${ }^{1}$
}

\begin{abstract}
Background: Atrial fibrillation (AF) increases risk of stroke, and although this stroke risk can be ameliorated by warfarin therapy, some patients decline to adhere to warfarin therapy. A prospective clinical study could be conducted to determine whether knowledge of genetic risk for AF could increase adherence to warfarin therapy for patients who initially declined therapy. As a prelude to a potential prospective clinical study, we investigated whether the use of genetic information to increase adherence could be cost effective.
\end{abstract}

Methods: Markov model assessed costs and utilities of two care strategies for AF patients who declined warfarin therapy. In the usual care strategy patients received aspirin. In the test strategy genetic risk for AF was assessed (genotype of the $4 q 25$ locus) and some patients with a positive genetic test ( $\geq 1$ risk allele) were assumed to adhere to warfarin therapy. The remaining patients received aspirin. The incremental cost-effectiveness ratio (ICER) was the ratio of the costs differential and the quality adjusted life-years (QALYs) differential for the two strategies.

Results: We found that the $4 \mathrm{q} 25$ genetic testing strategy, compared with the usual care strategy (aspirin therapy), would be cost-effective (ICER $\$ 47,148$ ) if $2.1 \%$ or more of the test positive patients were to adhere to warfarin therapy. The test strategy would become a cost saving strategy if $5.3 \%$ or more of the test positive patients were to adhere to warfarin therapy. If $20 \%$ of test positive patients were to adhere to warfarin therapy in a hypothetical cohort of 1000 patients, 7 stroke events would be prevented and 3 extra-cranial major bleeding events would be caused over 5 years, resulting in a cost savings of $\sim \$ 250,000$ and a net gain of 9 QALYs.

Discussion: A clinical study to assess the impact of patient knowledge of genetic risk of AF on adherence to warfarin therapy would be merited because even a modest increase in patient adherence would make a genetic testing strategy cost-effective.

Conclusion: Providing patients who declined warfarin therapy with information about their genetic risk of AF would be cost effective if this genetic risk information resulted in modest increases in adherence.

Keywords: $4 \mathrm{q} 25$ genetic test, Adherence, Cost effectiveness

\section{Background}

Atrial fibrillation (AF) is a common heart rhythm disorder affecting about 2.4 million people in the US $[1,2]$, and this number is projected to exceed 5.6 million by 2050 [3]. AF is associated with a 5 -fold greater risk of embolic stroke $[4,5]$ and accounts for 75,000 to 100,000 strokes per year in the US [4]. The risk of stroke due to AF can be reduced by about $50 \%$ with oral anticoagulants such as warfarin

\footnotetext{
* Correspondence: dov.shiffman@questdiagnostics.com

'Quest Diagnostics, 1401 Harbor Bay Parkway, Alameda, CA 94502, USA

Full list of author information is available at the end of the article
}

$[6,7]$, and current American Heart Association and American Stroke Association (AHA/ASA) guidelines recommend prophylactic therapy with warfarin for high and moderate risk AF patients [8]. Despite strong evidence supporting its efficacy, adherence to warfarin therapy is low-among patients who started warfarin therapy for AF, more than 1 in 4 patients discontinue warfarin therapy within one year $[9,10]$. Low adherence to warfarin therapy is driven by patient concerns about potential bleeding events and the need for continued periodic blood tests

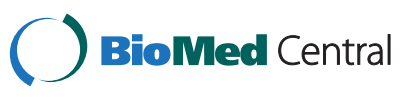

(C) 2015 Shiffman et al. Open Access This article is distributed under the terms of the Creative Commons Attribution 4.0 International License (http://creativecommons.org/licenses/by/4.0/), which permits unrestricted use, distribution, and reproduction in any medium, provided you give appropriate credit to the original author(s) and the source, provide a link to the Creative Commons license, and indicate if changes were made. The Creative Commons Public Domain Dedication waiver (http://creativecommons.org/publicdomain/zero/1.0/) applies to the data made available in this article, unless otherwise stated. 
(prothrombin time/International Normalized Ratio (INR)) to monitor the patient's response to warfarin [11-14].

Any strategy that would increase adherence to warfarin therapy among eligible AF patients has the potential to prevent fatal and non-fatal stroke events. Strategies for increasing adherence to warfarin that have been previously investigated include counseling $[15,16]$, the use of decision aids [16], as well as self-testing and self-management programs [17]. Providing patients with information about their genetic-based risks also has the potential to improve adherence and ultimately clinical outcomes. A recent study reported that patients with a genetic diagnosis of familial hypercholesterolemia were $\sim 50 \%$ more adherent to treatment than were patients without a genetic diagnosis [18]. Similarly, patients' knowledge of genetic test results increased adherence (63 vs. $45 \%$ ) to statin therapy in the AKROBATS study [19].

Since gene variants in the $4 q 25$ region of the human genome are associated with increased risk of AF and stroke [20], providing 4q25 genetic test results to patients might increase adherence to warfarin therapy. If this strategy could be cost effective, it might justify conducting a clinical trial to test the hypothesis that genetic test results would increase adherence to warfarin therapy, which may lead to a lower incidence of preventable strokes. In order to provide cost effectiveness estimates that could be used to justify or design such a clinical trial, we investigated whether the use of genetic information to increase adherence could be cost effective over a range of adherence rates.

\section{Methods}

\section{Model structure and overview}

Our analysis considered a hypothetical population of 1000 patients with AF who were prescribed warfarin to prevent future ischemic stroke events but who declined to adhere to warfarin therapy. We developed a Markov model to evaluate the payer-perspective cost-effectiveness of two patient care strategies (Fig. 1). One strategy is usual care: patients who refused warfarin therapy received aspirin therapy. The other strategy is a test strategy: patients were tested for genotypes of two variants in the 4q25 locus (rs2200733 and rs10033464). A fraction of patients with positive test results (having at least 1 risk allele of either variant) were assumed to be motivated to adhere to warfarin therapy. The remaining patients in the test strategy received aspirin therapy. The model compared expected costs and outcomes of these two strategies. Incremental cost-effectiveness ratios (ICERs) were calculated as the difference in costs between the usual care strategy and the test strategy divided by the difference in outcomes (expressed in quality adjusted life years, (QALYs) between the two strategies.

The model (Fig. 1) estimates the number of fatal and non-fatal stroke events, fatal and non-fatal major bleeding events, costs for drug and hospitalization, as well as QALYs in each strategy over a 5-year horizon using a 1year cycle time. We assumed that warfarin reduced the annual rate of stroke compared with aspirin [21], that the rate of major bleeding events was lower among aspirin users compared with warfarin users [21], and that $40 \%$ of the patients will have a positive genetic test result, based on the reported allele frequencies for these genetic variants [20].

The incidence of stroke and major bleeding events was calculated for each strategy over a 5 year time horizon using annual event rates for warfarin and aspirin as appropriate. We assumed that warfarin therapy will be discontinued for those patients who would experience an intracranial bleeding or other major bleeding event and that those patients on aspirin therapy would convert to warfarin therapy after an ischemic stroke event. For both strategies, we assumed that patients who initially declined warfarin therapy would convert to warfarin at an annual rate of $2.5 \%$. This annual rate of conversion to warfarin would be 2-fold more likely for test-positive patients who initially declined warfarin and 2-fold less likely for test-negative patients. One-time and subsequent monthly costs of stroke and major bleeding events were based on published 2005 estimates. A $3 \%$ annual

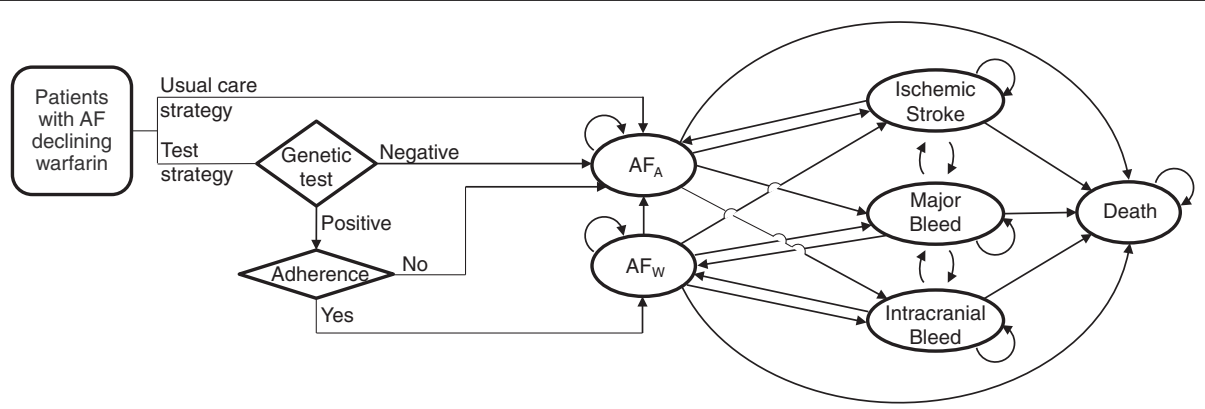

Fig. 1 Schematic representation of patient care strategies and Markov model. Diamonds represent decision nodes, ovals represent Markov states. Arrows represent potential transitions between decision nodes and states. Abbreviations: $\mathrm{AF}_{\mathrm{A}}$, atrial fibrillation patients on aspirin therapy; $\mathrm{AF}_{\mathrm{W}}$ atrial fibrillation patients on warfarin therapy 
discount rate was applied to costs and utilities. Patient utility estimates for stroke, intracranial bleeding, and other major bleeding events were based on published estimates. Patients with fatal events were assigned a utility weight of 0 . A summary of base case event rates, utilities, and costs as well as the respective sources for these values is provided in Table 1.

\section{Sensitivity analyses}

The adherence rates to warfarin among those with a positive $4 \mathrm{q} 25$ test result were varied from 1 to $50 \%$ using base-case values. Sensitivity analyses were performed to examine the effect of varying key parameter estimates. One-way sensitivity analysis included the following parameters: the annual rate of stroke among aspirin users (varied between 3 and $6 \%$ ), the risk reduction of stroke by warfarin compared with aspirin (0.37 to 0.63 ), the annual rate of major bleeds among warfarin users (2 to $4 \%$ ), the relative risk of major bleeds by aspirin compared with warfarin $(0.5$ to 0.7 ), the cost of genetic testing ( $\$ 50$ to $\$ 200$ ), the costs associated with events (strokes, major bleeds) and drugs (varied simultaneously $50 \%$ above and below the base-case values), and utility estimates of the non-fatal states in the model (varied simultaneously $20 \%$ above and below the base-case values). A probabilistic sensitivity analysis (PSA) was performed using a Monte Carlo simulation of 10,000 trials by drawing the values of the baseline parameters from triangular distributions. The contribution of baseline parameters to the variation observed in PSA was evaluated from the correlation between the variance of

Table 1 Model Variables: base case patient probabilities, costs, and utility estimates

\begin{tabular}{|c|c|c|c|}
\hline Variable & Base-Case & Range & Reference \\
\hline \multicolumn{4}{|l|}{ Probabilities } \\
\hline Baseline rate of stroke on aspirin, \%/year & 4.5 & $3-6$ & {$[23,24]$} \\
\hline Relative risk of stroke with warfarin compared with aspirin & 0.48 & $0.37-0.63$ & {$[23,24]$} \\
\hline Baseline rate of major hemorrhage (including $\mathrm{ICH}$ ) on warfarin, \%/year & 2.5 & $2-4$ & {$[23,24]$} \\
\hline Relative risk of hemorrhage with aspirin compared with warfarin & 0.59 & $0.50-0.70$ & [23] \\
\hline Fraction of $\mathrm{ICH}$ among major hemorrhage events & 0.2 & NA & [22] \\
\hline Fraction of fatal strokes among stroke events on warfarin & 0.082 & NA & [24] \\
\hline Fraction of fatal strokes among stroke events on aspirin & 0.179 & NA & [24] \\
\hline Fraction of fatal events among $\mathrm{ICH}$ & 0.364 & NA & [25] \\
\hline Fraction of fatal major hemorrhages (excluding $\mathrm{ICH}$ ) & 0.049 & NA & [25] \\
\hline \multicolumn{4}{|l|}{ Costs (\$) } \\
\hline Warfarin annual cost & 180 & $\pm 50 \%$ & [24] \\
\hline Aspirin annual cost & 10 & $\pm 50 \%$ & [24] \\
\hline Fatal ischemic stroke & 12130 & $\pm 50 \%$ & Assumption, based on [24] \\
\hline Average one-time cost of non-fatal stroke on warfarin & 9667 & $\pm 50 \%$ & Calculated based on [24] \\
\hline Average monthly cost of non-fatal stroke on warfarin & 2652 & $\pm 50 \%$ & Calculated based on [24] \\
\hline Average one-time cost of non-fatal stroke on aspirin & 9610 & $\pm 50 \%$ & Calculated based on [24] \\
\hline Average monthly cost of non-fatal stroke on aspirin & 2168 & $\pm 50 \%$ & Calculated based on [24] \\
\hline Intracoronary hemorrhage $(\mathrm{ICH})$ one-time cost & 31810 & $\pm 50 \%$ & {$[24,26,27]$} \\
\hline Intracoronary hemorrhage $(\mathrm{ICH})$ monthly costs & 4690 & $\pm 50 \%$ & {$[24,26,27]$} \\
\hline Major hemorrhage (excluding ICH) & 3620 & $\pm 50 \%$ & {$[24,26,27]$} \\
\hline \multicolumn{4}{|l|}{ Utilities } \\
\hline Healthy on warfarin & 0.987 & unchanged & {$[28,29]$} \\
\hline Healthy on aspirin & 0.998 & unchanged & {$[28,29]$} \\
\hline Non-fatal stroke on warfarin, weighted average & 0.476 & $\pm 20 \%$ & [24] \\
\hline Non-fatal stroke on aspirin, weighted average & 0.426 & $\pm 20 \%$ & [24] \\
\hline Non-fatal ICH & 0.4 & $\pm 20 \%$ & Assumption \\
\hline Recurrent stroke & 0.12 & $\pm 20 \%$ & [29] \\
\hline
\end{tabular}


each parameter in the PSA model and the variance of the PSA outcome.

\section{Results}

\section{Base-case analysis}

We estimated the costs and utilities over a 5 year horizon of two health-care strategies among 1000 patients with AF who were prescribed warfarin to prevent future ischemic stroke events but who had declined warfarin therapy. The first strategy was usual care (aspirin therapy and no genetic test). The second strategy (test strategy) used genetic testing for risk of AF to motivate patients to adhere to the prescribed warfarin therapy (Fig. 1). We modeled testing of two genetic variants associated with risk of AF in the 4q25 locus (rs2200733 and rs10033464). We assumed that those who carry at least 1 risk allele of either variant (test positive) would be motivated to adhere to warfarin therapy. We first investigated the fraction of the test positive patients that would need to adhere to warfarin therapy in order to make the test strategy cost effective. We found that under the base-case assumptions (Table 1), the test strategy would be cost-effective compared with the usual care (cost/QALY $=\$ 47,148)$ if $2.1 \%$ or more of the test positive patients choose to adhere to warfarin therapy. The test strategy would become a cost saving strategy if more than $5.3 \%$ of the test positive patients adhere to warfarin therapy (Fig. 2). And, if $20 \%$ of the test positive patients adhere to warfarin therapy, 7 stroke events would be prevented and 3 extra-cranial major bleeding events would be caused for every 1000 patients tested. That is, the test strategy would dominate the usual care strategy: the test strategy would result in better outcomes (a net gain of 9 QALYs) and lower costs (a net saving of $\sim \$ 250,000)$ over a 5 year horizon compared with the usual care strategy (Table 2).

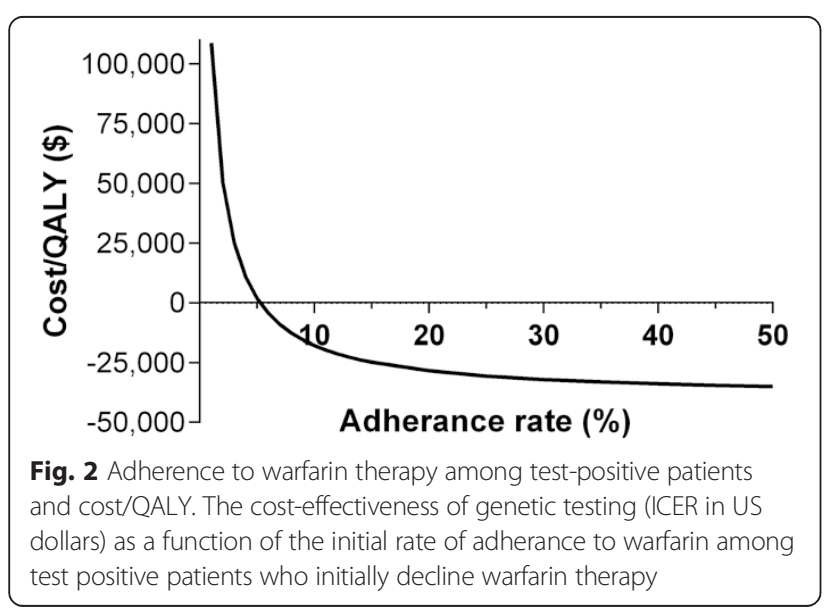

Table 2 Cost savings and utility gains of the test strategy compared with the usual care strategy for different adherence assumptions for 1000 patients

\begin{tabular}{llc}
\hline Adherence rate, $\%$ & Cost saving (loss), \$ & QALYs gained \\
\hline 1 & $(72,332)$ & 0.7 \\
2 & $(55,331)$ & 1.1 \\
3 & $(38,330)$ & 1.5 \\
4 & $(21,329)$ & 2.0 \\
5 & $(4,328)$ & 2.4 \\
7.5 & 38,175 & 3.5 \\
10 & 80,678 & 4.5 \\
15 & 165,683 & 6.7 \\
20 & 250,689 & 8.8 \\
25 & 335,694 & 11.0 \\
30 & 420,699 & 13.1 \\
40 & 590,710 & 17.5 \\
50 & 760,721 & 21.8 \\
\hline
\end{tabular}

\section{Sensitivity analyses}

We examined the effect of the uncertainty in the input parameters on the model outcome by varying individual parameters from their baseline values. We used a $5.25 \%$ adherence rate in the model to investigate the effect of baseline parameters when adherence rate would be cost neutral. We found that changing the input parameters had little effect on the cost-effectiveness of the test strategy compared with the usual care. When the parameters were within the ranges listed in Table 1 , the test strategy remained cost effective (ICER $<\$ 47,000$, Fig. 3). Moreover, varying the medical cost estimates, the bleeding rate among warfarin users, the relative bleeding rate among aspirin users vs. warfarin users, and the utility estimates all resulted in ICER estimates lower than $\$ 20,000$ at their most unfavorable limit. Using the low

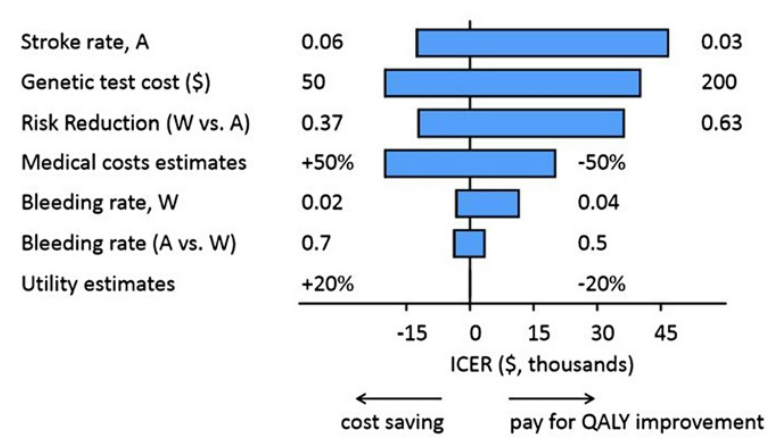

Fig. 3 One-way sensitivity analysis. The effect of varying baseline parameters over clinically and economically relevant ranges on ICER. Parameter values used are indicated to the left and to the right of each blue bar. Abbreviation used: A, asprin; W, warfarin 
end for the annual rate of stroke among aspirin users (3\%, compared with the baseline value of $4.5 \%$ ) resulted in an ICER of $\sim \$ 40,000$, which was the largest ICER range for any individual baseline parameter. Since the rate of stroke events differs among individuals according to their $\mathrm{CHADS}_{2}$ score [24], we investigated QALY gained and ICERs in a model for patients with different $\mathrm{CHADS}_{2}$ scores (Fig. 4). When the test strategy was compared with the usual care strategy among patients with a $\mathrm{CHADS}_{2}$ score of 3 and greater, the test strategy would be dominating the usual care strategy: it would be cost saving and result in progressively more QALYs gained compared with the usual care as $\mathrm{CHADS}_{2}$ score increased.

Using a probabilistic sensitivity analysis we investigated the contribution of each of these parameters to the overall variability of the ICER estimates. We found that 3 input parameters (the cost of genetic testing, annual stroke rate among AF patients who use aspirin, and the risk reduction of warfarin compared with aspirin) together account for more than $80 \%$ of the variability in the model (Fig. 5). Assuming $20 \%$ of the test positive patients adhered to warfarin therapy the test strategy was almost always (96.8\%) associated with lower cost and more QALYs than the usual care strategy (Fig. 6).

\section{Discussion}

We compared the usual care strategy with a strategy that used genetic testing to motivate AF patients who declined physician prescribed warfarin therapy to reconsider and initiate therapy. We found that the test strategy could be cost effective even if only $2.1 \%$ of test positive individuals adhered to warfarin therapy over a 5 year horizon. If less than $2 \%$ of test positive individuals would adhere to warfarin therapy, this strategy becomes prohibitively expensive, costing more than $\$ 100,000$ per QALY if adherence were to fall below $1 \%$. However, if adherence were to be greater than $5.3 \%$, this genetic test strategy would be cost-saving under the base-case assumptions.

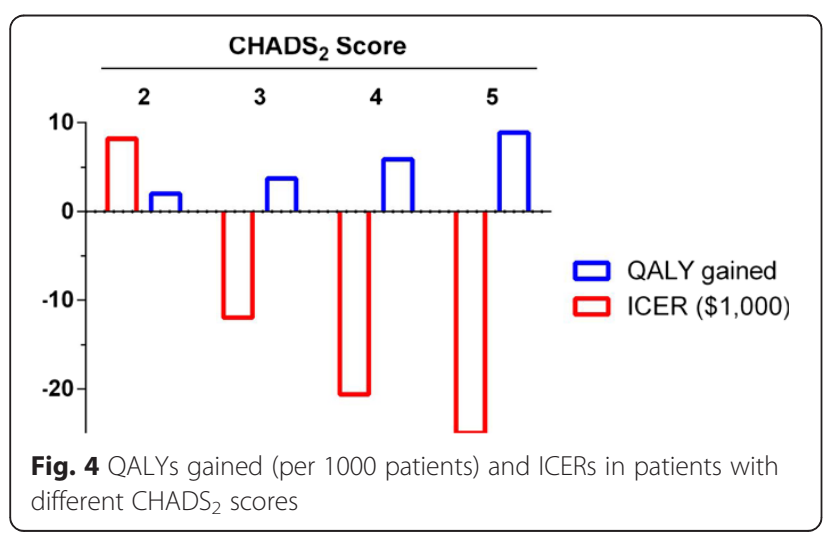

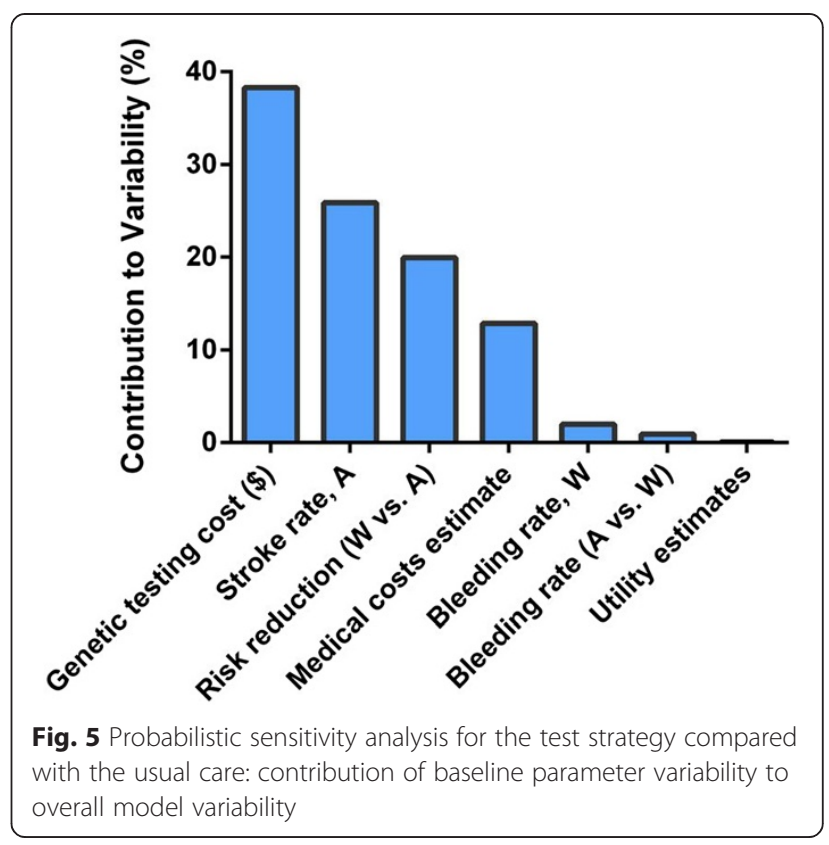

A $5.3 \%$ increase in adherence in response to genetic test information is smaller than what has been reported by in real-world studies. For example, among patients who were identified as having hypercholesterolemia based on their blood cholesterol levels, adherence to statin medication went up from 39 to $93 \%$ following a genetic confirmation of their diagnosis [18]. Similarly, among all-comers with a newly-prescribed statin therapy, adherence increased from 45 to $63 \%$ following genetic testing [19]. Thus, it seems that genetic testing results have the potential to increases in adherence of greater magnitude than that in the model we present. The specific effect of genetic testing on adherence to anticoagulation among patients with $\mathrm{AF}$ after genetic testing would need to be determined in a clinical study.

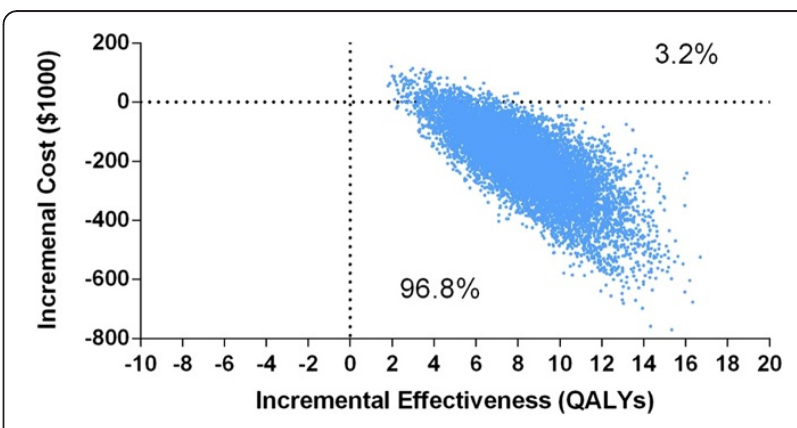

Fig. 6 Probabilistic sensitivity analysis for the test strategy compared with the usual care strategy assuming $20 \%$ of the test positive patients adhered to warfarin therapy. The cost-effectiveness plane shows the effect of simultaneously varying all model parameters on incremental cost (per 1000 patients, vertical axis) and incremental effectiveness (per 1000 patients, horizontal axis) in 10,000 Monte Carlo simulations 
The model baseline parameters were based on published information. The effect of these parameters on the ICERs predicted by the model was modest. The low end of annual rate of stroke events among AF patients who use aspirin (but decline warfarin) resulted in the biggest ICER using baseline parameters. That is, if annual stroke rate among AF patients on aspirin was $3 \%$, the ICER would be $\sim \$ 47,000$, however if the annual rate of stroke was at the high end (6\%) the genetic testing strategy would be dominating (cost-saving with better outcomes). Interestingly, if the annual rate of stroke among aspirin users were to be as low as $2 \%$, the number of strokes prevented by warfarin treatment would be offset by an equal number of major bleeds caused by warfarin treatment (1.5) regardless of treatment strategy. Conversely, a higher rate of strokes in subgroups of patients, which can be estimated by risk scores such as $\mathrm{CHADS}_{2}$, would make the test strategy more cost saving and gain more QALYs compared with the usual care strategy.

This study has several potential limitations. First, this study is based on a theoretical patient cohort and therefore used baseline parameters that were established in other real-life cohorts. Deviation from these baseline parameter estimates could affect the results. However, our sensitivity analyses established that variations in these parameters have only a small effect on the conclusions of this study. We found that the cost of the genetic test had the greatest influence on the range of total costs. We believe that the range of costs investigated (\$50 to \$200) was reasonable, because the genetic test considered in this study involved genotyping two single nucleotide polymorphisms (SNPs). And Medicare reimbursement for two SNPs was $\sim \$ 100$ in 2013-this is based on the combined reimbursement for the Factor $\mathrm{V}$ Leiden SNP and for the Factor II (20210G > A) SNP [31]. We have based all other medical costs on published 2005 estimates [25]. However, inflating these costs to 2014 would result in more favorable outcome for the test strategy since the test strategy results in fewer events than the usual care strategy for any adherence rate. Second, we focused our analysis on adherence to warfarin as an oral anticoagulant. We believe an investigation of adherence to warfarin is important because warfarin remains first line therapy (recommendation 1A) in the 2014 AHA/ACC guidelines for the management of patients with atrial fibrillation [30]. New oral anticoagulants (NOACs: dabigatran, rivaroxaban, and apixaban) which are now available as anticoagulant option for some AF patients received a $1 \mathrm{~B}$ recommendation. Patient adherence to NOACs is not likely better than to warfarin [31], presumably because bleeding event rates for warfarin are largely not different than that for most NOACs [32]. Moreover, the lack of approved antidote to
NOACs can deter some patients from adhering to therapy. Third, we assumed the frequency of individuals who are carriers of a 4q25 risk allele (test positive) to be $40 \%$. This assumption is based on the reported allele frequencies of rs2200733 and rs10033464 in populations of European ancestry. The fraction of test positive individuals could vary in populations with a different ethnic ancestry. For example, among Yoruban in Ibadan, Nigeria, the fraction of test positive patients would be $86 \%$ [33]. We elected to use the test positive information for European ancestry patients because most of the genetic association studies supporting the association of these SNPs with risk of AF were conducted in these populations. Our model could be easily adopted for other expected test positive fractions. Given these limitations, the results of this study should be cautiously considered when trying to extrapolate to real-life studies.

\section{Conclusions}

In conclusion, we have demonstrated that under a wide range of input parameters, genetic testing to motivate adherence to warfarin therapy among AF patients eligible for this therapy would be cost effective. The range of cost effective adherence rates identified in this model could be used to aid in design of a clinical study that would test whether providing patients with information about their genetic AF risk would improve their adherence to warfarin therapy.

\section{Competing interests}

$D S, L B, J L, A A$, and JD are employees of Quest Diagnostics. MP declares no competing interests.

\section{Authors' contributions}

$D S, M P$ and JD participated in the design of the study. AA, JL and LB performed the statistical analysis. DS, MP and JD conceived of the study, and participated in its design and coordination. AA, DS, JL, JD, LB, and MP helped to draft the manuscript. All authors read and approved the final manuscript.

Authors' information

Not applicable.

Funding

This study was funded by Quest Diagnostics.

\section{Author details}

1Quest Diagnostics, 1401 Harbor Bay Parkway, Alameda, CA 94502, USA. ${ }^{2}$ Stanford University School of Medicine, 291 Campus Drive, Stanford, CA 94305, USA.

Received: 19 February 2015 Accepted: 18 September 2015 Published online: 29 September 2015

\section{References}

1. Heeringa J, van der Kuip DA, Hofman A, Kors JA, van Herpen G, Stricker BH, et al. Prevalence, incidence and lifetime risk of atrial fibrillation: the Rotterdam study. Eur Heart J. 2006;27(8):949-53. doi:10.1093/eurheartj/ ehi825.

2. Fuster V, Ryden LE, Cannom DS, Crijns HJ, Curtis AB, Ellenbogen KA, et al. 2011 ACCF/AHA/HRS focused updates incorporated into the ACC/AHA/ESC 2006 Guidelines for the management of patients with atrial fibrillation: a report of the American College of Cardiology Foundation/American Heart 
Association Task Force on Practice Guidelines developed in partnership with the European Society of Cardiology and in collaboration with the European Heart Rhythm Association and the Heart Rhythm Society. J Am Coll Cardiol. 2011;57(11):e101-98. doi:10.1016/j.jacc.2010.09.013.

3. Go AS, Hylek EM, Phillips KA, Chang Y, Henault LE, Selby JV, et al. Prevalence of diagnosed atrial fibrillation in adults: national implications for rhythm management and stroke prevention: the AnTicoagulation and Risk Factors in Atrial Fibrillation (ATRIA) Study. JAMA. 2001;285(18):2370-5.

4. Wolf PA, Abbott RD, Kannel WB. Atrial fibrillation as an independent risk factor for stroke: the Framingham Study. Stroke. 1991;22(8):983-8.

5. Kannel WB, Benjamin EJ. Status of the epidemiology of atrial fibrillation. Med Clin North Am. 2008;92(1):17-40. doi:10.1016/j.mcna.2007.09.002. ix

6. Hart RG, Benavente O, McBride R, Pearce LA. Antithrombotic therapy to prevent stroke in patients with atrial fibrillation: a meta-analysis. Ann Intern Med. 1999;131(7):492-501.

7. Risk factors for stroke and efficacy of antithrombotic therapy in atrial fibrillation. Analysis of pooled data from five randomized controlled trials. Archives of internal medicine. 1994;154(13):1449-57.

8. Furie KL, Goldstein LB, Albers GW, Khatri P, Neyens R, Turakhia MP, et al. Oral antithrombotic agents for the prevention of stroke in nonvalvular atrial fibrillation: a science advisory for healthcare professionals from the American Heart Association/American Stroke Association. Stroke. 2012;43(12):3442-53. doi:10.1161/STR.0b013e318266722a.

9. Fang MC, Go AS, Chang Y, Borowsky LH, Pomernacki NK, Udaltsova $N$, et al. Warfarin discontinuation after starting warfarin for atrial fibrillation. Circ Cardiovasc Qual Outcomes. 2010;3(6):624-31. doi:10.1161/ CIRCOUTCOMES.110.937680.

10. Gomes T, Mamdani MM, Holbrook AM, Paterson JM, Juurlink DN. Persistence with therapy among patients treated with warfarin for atrial fibrillation. Arch Intern Med. 2012;172(21):1687-9. doi:10.1001/ archinternmed.2012.4485

11. Elkind MS, Sacco RL. Direct thrombin inhibition: a novel approach to stroke prevention in patients with atrial fibrillation. Stroke. 2004;35(6):1519-22. doi:10.1161/01.STR.0000128883.89984.52

12. Blich M, Gross B. Thromboembolic prophylaxis in nonrheumatic atrial fibrillation: utilization patterns, efficacy, and complications in a long-term follow-up of community patients. Int J Cardiol. 2004;96(1):89-95. doi:10.1016/j.ijcard.2003.06.014.

13. Donnan GA, Dewey HM, Chambers BR. Warfarin for atrial fibrillation: the end of an era? Lancet Neurol. 2004;3(5):305-8. doi:10.1016/S1474-4422(04)00738-0.

14. Garwood CL, Corbett TL. Use of anticoagulation in elderly patients with atrial fibrillation who are at risk for falls. Ann Pharmacother. 2008;42(4):523-32. doi:10.1345/aph.1K498.

15. Mazor KM, Baril J, Dugan E, Spencer F, Burgwinkle P, Gurwitz JH. Patient education about anticoagulant medication: is narrative evidence or statistical evidence more effective? Patient Educ Couns. 2007:69(1-3):145-57. doi:10.1016/.jpec.2007.08.010.

16. McAlister FA, Man-Son-Hing M, Straus SE, Ghali WA, Anderson D, Majumdar SR, et al. Impact of a patient decision aid on care among patients with nonvalvular atrial fibrillation: a cluster randomized trial. CMAJ. 2005;173(5): 496-501. doi:10.1503/cmaj.050091.

17. Bloomfield HE, Krause A, Greer N, Taylor BC, MacDonald R, Rutks I, et al. Meta-analysis: effect of patient self-testing and self-management of longterm anticoagulation on major clinical outcomes. Ann Intern Med. 2011:154(7):472-82. doi:10.7326/0003-4819-154-7-201 104050-00005.

18. Umans-Eckenhausen MA, Defesche JC, van Dam MJ, Kastelein JJ. Long-term compliance with lipid-lowering medication after genetic screening for familial hypercholesterolemia. Arch Intern Med. 2003;163(1):65-8.

19. Charland SL, Agatep BC, Herrera V, Schrader B, Frueh FW, Ryvkin M, et al. Providing patients with pharmacogenetic test results affects adherence to statin therapy: results of the Additional KIF6 Risk Offers Better Adherence to Statins (AKROBATS) trial. The pharmacogenomics J. 2013;14(3):272-80. doi:10.1038/tpj.2013.27.

20. Kääb S, Darbar D, van Noord C, Dupuis J, Pfeufer A, Newton-Cheh C, et al. Large scale replication and meta-analysis of variants on chromosome $4 \mathrm{q} 25$ associated with atrial fibrillation. Eur Heart J. 2009:30(7):813-9. doi:10.1093/ eurheartj/ehn578.

21. Hart RG, Palacio S, Pearce LA. Atrial fibrillation, stroke, and acute antithrombotic therapy: analysis of randomized clinical trials. Stroke. 2002;33(11):2722-7.
22. Copland M, Walker ID, Tait RC. Oral anticoagulation and hemorrhagic complications in an elderly population with atrial fibrillation. Arch Intern Med. 2001;161(17):2125-8.

23. Kamel H, Hegde M, Johnson DR, Gage BF, Johnston SC. Cost-effectiveness of outpatient cardiac monitoring to detect atrial fibrillation after ischemic stroke. Stroke. 2010:41(7):1514-20

24. O'Brien CL, Gage BF. Costs and effectiveness of ximelagatran for stroke prophylaxis in chronic atrial fibrillation. JAMA. 2005;293(6):699-706. doi:10.1001/jama.293.6.699.

25. Coleman Cl, Straznitskas AD, Sobieraj DM, Kluger J, Anglade MW. Cost-effectiveness of clopidogrel plus aspirin for stroke prevention in patients with atrial fibrillation in whom warfarin is unsuitable. Am J Cardiol. 2012;109(7):1020-5. doi:10.1016/j.amjcard.2011.11.034.

26. Leibson CL, Hu T, Brown RD, Hass SL, O'Fallon WM, Whisnant JP. Utilization of acute care services in the year before and after first stroke: A populationbased study. Neurology. 1996;46(3):861-9.

27. Holloway RG, Witter Jr DM, Lawton KB, Lipscomb J, Samsa G. Inpatient costs of specific cerebrovascular events at five academic medical centers. Neurology. 1996;46(3):854-60

28. Freeman JV, Zhu RP, Owens DK, Garber AM, Hutton DW, Go AS, et al. Costeffectiveness of dabigatran compared with warfarin for stroke prevention in atrial fibrillation. Ann Intern Med. 2011;154(1):1-11. doi:10.7326/0003-4819154-1-201101040-00289.

29. Gage BF, Cardinalli AB, Owens DK. The effect of stroke and stroke prophylaxis with aspirin or warfarin on quality of life. Arch Intern Med. 1996;156(16):1829-36.

30. January CT, Wann LS, Alpert JS, Calkins H, Cigarroa JE, Cleveland Jr JC, et al. AHA/ACC/HRS guideline for the management of patients with atrial fibrillation: a report of the American College of Cardiology/American Heart Association Task Force on Practice Guidelines and the Heart Rhythm Society. J Am Coll Cardiol. 2014;64(21):e1-76. doi:10.1016/j.jacc.2014.03.022. Epub 2014 Mar 28.

31. Ten Cate H. New oral anticoagulants: discussion on monitoring and adherence should start now! Thromb J. 2013;11(1):8. doi:10.1186/1477-9560-11-8.

32. Stambler BS. A new era of stroke prevention in atrial fibrillation: comparing a new generation of oral anticoagulants with warfarin. Int Arch Med. 2013:6(1):46, doi:10.1186/1755-7682-6-46

33. International HapMap Project. http://hapmap.ncbi.nlm.nih.gov/. Accessed July 10, 2013.

\section{Submit your next manuscript to BioMed Central and take full advantage of:}

- Convenient online submission

- Thorough peer review

- No space constraints or color figure charges

- Immediate publication on acceptance

- Inclusion in PubMed, CAS, Scopus and Google Scholar

- Research which is freely available for redistribution 